
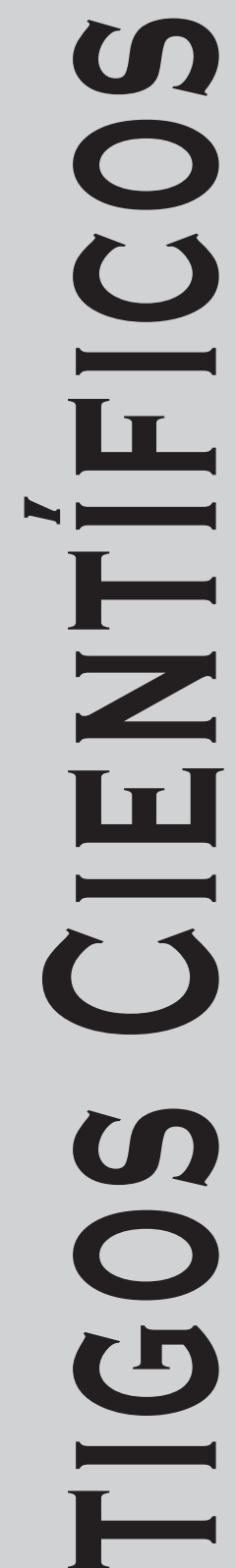
ac

Revista Música Hodie, Goiânia - V.14, 238p., n.1, 2014 


\title{
O Efeito de Atividades de Execução, Composição e Apreciação Musical sobre a Percepção de Timbres
}

\author{
Caroline Caregnato (Universidade do Estado do Amazonas, Manaus, AM; Universidade Estadual de \\ Campinas, Campinas, SP) \\ carolinecaregnato@gmail.com
}

\begin{abstract}
Resumo: Este trabalho teve como objetivo geral investigar o efeito da aprendizagem musical sobre a percepção de timbres. Mais especificamente, o que se buscou foi investigar o efeito que a realização de atividades de execução, apreciação e composição musical teria sobre essa percepção. Neste trabalho foi realizado um estudo experimental envolvendo 51 crianças de 6 a 9 anos de idade. Os participantes do estudo foram divididos em um grupo controle e três grupos experimentais. Todos os grupos foram submetidos a um teste de percepção de timbres. Cada um dos grupos experimentais realizou, antes do teste, uma atividade musical focada na execução, ou na composição ou na apreciação musical. O grupo controle não realizou nenhuma atividade. Os resultados observados apontaram para a existência de uma diferença significativa entre o desempenho dos grupos experimentais e do grupo controle, comprovando assim a hipótese levantada incialmente de que a educação musical favoreceria a percepção de timbres.
\end{abstract}

Palavras-chave: Percepção musical; Percepção de timbres; Execução musical; Apreciação musical; Composição musical.

The Effect of Activities of Musical Execution, Composition and Listening on Timbre Perception

Abstract: This paper aims to investigate the effect of musical learning on timbre perception. More specifically, it aims to investigate the effect of the musical activities of execution, listening and composition on timbre perception. in this work was realized an experimental study with 51 six and nine-years-old children. The participants were divided in one control group and three experimental groups. All groups were submitted to a timbre perception test. Each experimental group did, before the test, a musical activity focused in performance, or appreciation or composition. The control group did no musical activity. The results observed show the existence of a significant difference between the performance of the control and experimental groups, proving the hypothesis initially presented that musical education could affect timbre perception.

Keywords: Musical perception; Timbre perception; Musical performance; Musical appreciation; Musical composition.

\section{Introdução}

O timbre pode ser definido como um atributo complexo do som, responsável por permitir a discriminação entre dois tons que sejam idênticos em altura, intensidade e duração (AGUS; SUIED; TORPE; PRESSNITZER, 2012; AUCOUTURIER; PACHET, 2006; HÁDEN; STEFANICS; VESTERGAARD; DENHAM; SZILLER; WINKLER, 2009; IVERSON; KRUMHANSL, 1993; SAMSOM; ZATORRE, 1994).

Iverson e Krumhansl (1993) observaram que uma identificação de timbres apurada depende da percepção dos ataques sonoros. A percepção do ataque permite ao ouvinte definir temporalmente a forma como o som foi produzido: se através de golpes, por meio do sopro ou através da fricção de um arco, por exemplo. Paquette e Peretz (1997) ainda mencionam que a percepção do timbre depende da identificação do conteúdo espectral do som, ou seja, do número e da amplitude de frequência dos harmônicos sonoros. Em síntese, a percepção do timbre depende da percepção de variações temporais (relacionadas ao ataque sonoro) e da percepção do espectro de energia sonora (harmônicos do som) (SAMSOM; ZATORRE, 1994).

O cérebro pode ser identificado como o local onde esses aspectos do som são processados, gerando a percepção de timbres. Uma pesquisa realizada por Paquette e Peretz (1997) com 12 não-músicos, estudantes universitários investigou qual é o hemisfério cere- 
bral mais ativado durante a percepção de timbres. Os autores utilizaram melodias familiares e não-familiares em seu trabalho a fim de testar a hipótese de que durante a percepção de timbres em melodias familiares haveria grande ativação do hemisfério esquerdo, responsável por determinados tipos de memória. A pesquisa de Paquette e Peretz (1997) demostrou, contudo, que o lado direito do cérebro é especialmente ativado durante a percepção de timbres tanto em melodias não familiares quanto em melodias familiares. Dados semelhantes a esses também foram encontrados por Samsom e Zatorre (1994) e por Brancucci e Martini (1999). Ainda segundo o estudo de Paquette e Peretz (1997), o reconhecimento do timbre de músicas não familiares é mais difícil que o reconhecimento de timbres em músicas conhecidas. É possível, portanto, que mesmo com um alto nível de atividade cerebral no hemisfério direito, a memória também intervenha na percepção do timbre de melodias conhecidas, ajudando a acelerar essa percepção.

O modo como o timbre é percebido também foi estudado por Agus, Suied, Torpe e Pressnitzer (2012). Eles observaram que o tempo de reconhecimento da entrada de novos timbres em uma música pode ser de poucas centenas de milissegundos. Segundo as observações dos pesquisadores, o tempo necessário para o reconhecimento de vozes é consideravelmente menor que o tempo necessário para a percepção de timbres de instrumentos de percussão e de cordas. Para os autores, essa rapidez no reconhecimento pode ser explicada pela presença de propriedades acústicas na voz não encontradas nos instrumentos de percussão ou de cordas. Pode ocorrer ainda graças a um processamento cerebral diferenciado da voz que seja inato ao aprendido, ou pode ser devido ao uso de processos de atenção adicionais, recrutados no momento em que ocorre o reconhecimento da voz. É provável que essa rapidez tenha origens evolutivas e que o sistema auditivo tenha se desenvolvido em benefício do processamento de sons vocálicos. Os autores também reforçam a possibilidade de essa rapidez ser fruto de processos de aprendizagem.

A percepção de timbres parece se desenvolver desde muito cedo, até mesmo antes do nascimento. Estudos têm mostrados que por volta da $20^{\mathrm{a}}$ semana de gestação os bebês já se mostram sensíveis a esse aspecto sonoro (HÁDEN; STEFANICS; VESTERGAARD; DENHAM; SZILLER; WINKLER, 2009).

Bebês de oito meses de idade também se mostraram sensíveis a aspectos acústicos que determinam a percepção de timbres vocais e que, por consequência, determinam o reconhecimento de objetos, a expressão vocal de emoções e o estabelecimento de interações sociais (TSANG; TRAINOR, 2002).

Háden, Stefanics, Vestergaard, Denham, Sziller e Winkler, (2009) estudaram a percepção de timbres em bebês com 2 e 3 dias de vida. Eles expuseram os participantes de seu estudo à audição de sons de diferentes timbres e alturas iguais, e observaram que as crianças conseguiram perceber a invariância da altura. Esse dado sugere que os bebês possuem a capacidade de distinguir entre variações de timbre e variações de altura e que, portanto, a criança é capaz de formar representações mentais para esses dois parâmetros sonoros desde cedo.

Trainor, Wu e Tsang (2004) ainda sugerem que a formação de representações confere aos bebês a capacidade de memorizar melodias por longos períodos de tempo. Esses pesquisadores observaram em seu estudo a capacidade de memorização de andamentos e de timbres em bebês de 6 meses de idade. De acordo com os resultados do trabalho, os bebês demonstraram memorizar o andamento e o timbre de melodias familiares por longos períodos. Esses dados sugerem ainda que as crianças não retêm na memória apenas abstrações da estrutura geral da música, mas também de elementos de "superfície" relacionados à performance, como o timbre e o andamento. Trainor, Wu e Tsang (2004) ponderam que a 
aprendizagem parece ter efeitos sobre o desenvolvimento dessas representações de timbre e andamento realizadas pelos bebês, mas afirmam que mais estudos são necessários para que essa hipótese seja comprovada.

O efeito da aprendizagem musical sobre a percepção de timbres também foi estudado por Shahin, Roberts, Chau, Trainor e Miller (2008). Eles observaram que houve um alto nível de ocorrência de um tipo de atividade cerebral durante a identificação de timbres por adultos que tocavam um instrumento musical. Essa atividade foi menor em não-músicos. Dados coletados junto a crianças estudantes de piano e não estudantes de música também apontam nessa mesma direção: os alunos de música demonstram maior ativação cerebral que aqueles que não receberam nenhum tipo de instrução musical formal. Esses dados sugerem que a aprendizagem de um instrumento pode favorecer o desenvolvimento de atividades cerebrais responsáveis pela percepção de timbres.

Embora trabalhos como os de Shahin, Roberts, Chau, Trainor e Miller (2008), Agus, Suied, Torpe e Pressnitzer (2012) e Trainor, Wu e Tsang (2004) sugiram que a aprendizagem tem efeitos sobre a percepção de timbres, outros estudos tem apontado em direção oposta. Ao estudarem a percepção de alterações no timbre vocal, Bergan, Titze e Story (2004) não encontraram diferenças significativas entre o desempenho de participantes que haviam estudado música e o desempenho de não-músicos. Os participantes do estudo foram convidados a identificar diferentes níveis de alteração na formante de cantores (aspecto acústico que define o timbre das vozes), e a identificar a quantidade de adução (fechamento) das pregas vocais (a quantidade de adução torna a voz mais ou menos "branca”). Foram estudados não-músicos com nenhum ou leve nível de instrução musical, e músicos com no mínimo um curso de bacharelado em música completo.

Uma pesquisa conduzida por Lutfi, Oh, Storm e Alexander (2005) também mostrou que o estudo de um instrumento musical não torna as pessoas mais aptas a distinguir sons reais de sons sintetizados, produzidos com timbres de computador. Os músicos da Orquestra Sinfônica de Madison, que foram observados por esses pesquisadores, não tiveram um desempenho superior ao demonstrado pelos estudantes de um curso de graduação, não-músicos. Os autores sugerem que esse desempenho elevado dos não-músicos seja devido a qualidades acústicas inerentes aos sons sintetizados usados durante a pesquisa e que eram claramente distintos dos sons reais empregados. Também é possível que se pergunte qual era a vivência, enquanto ouvintes, dos não-músicos estudados. É possível que eles tenham vivenciado situações informais de aprendizagem relacionadas à apreciação musical que os tenha levado a desenvolver a competência de identificar timbres.

A aprendizagem musical evidentemente não se restringe apenas à aprendizagem da execução ${ }^{1}$ de um instrumento. Como aponta Swanwick (1979) em seu modelo (T) EC(L)A, um aluno pode se envolver com a aprendizagem direta de música através de atividades de execução, composição e apreciação musical. De acordo com a revisão de literatura realizada neste trabalho, se pode observar que o estudo dos efeitos da aprendizagem musical sobre a percepção do timbre tem se restringido à observações dos efeitos da aprendizagem de um instrumento (aprendizagem da execução musical). Faltam pesquisas que investiguem os efeitos dos outros tipos de atividades musicais (composição e apreciação) sobre o desenvolvimento da percepção de timbres. Este trabalho busca estudar essa questão.

O objetivo desta pesquisa é investigar o efeito da aprendizagem musical sobre a percepção de timbres. Mais especificamente, busca-se investigar o efeito que a realização de atividades de ensino/aprendizagem envolvendo a execução, a apreciação e a composição musical teria sobre a percepção de timbres. 
Como algumas pesquisas (SHAHIN; ROBERTS; CHAU; TRAINOR; MILLER, 2008; AGUS; SUIED; TORPE; PRESSNITZER, 2012; TRAINOR, WU e TSANG, 2004) têm mostrado que instrumentistas, experientes no trabalho de execução musical, costumam apresentar melhor percepção de timbres que não-músicos (pessoas que não executam um instrumento), acreditamos que a aprendizagem de música por meio da execução musical possa favorecer o desenvolvimento da identificação de instrumentos. $\mathrm{O}$ ensino de composição também pode favorecer o desenvolvimento dessa identificação porque durante essa atividade os alunos frequentemente criam e executam simultaneamente as suas peças.

Contudo, outros autores (BERGAN; TITZE; STORY, 2004; LUTFI; OH; STORM; ALEXANDER, 2005) também tem observado que não existem diferenças consideráveis entre a percepção de timbres de músicos e de não-músicos, ou seja, entre a percepção de pessoas que fazem música e de pessoas que apenas apreciam música. Dessa forma, é possível também que a realização de atividades de apreciação contribua tanto quanto a realização de atividades de execução ou de composição para o desenvolvimento da percepção de timbres.

Portanto, esta pesquisa parte da hipótese de que a aprendizagem de música por meio da realização de atividades de execução, composição e apreciação musical poderia favorecer o desenvolvimento da percepção de timbres.

Essa hipótese pode ser sustentada pelo fato de a realização de atividades de execução, composição e apreciação musical contribuir para a memorização de timbres. De acordo com Paquette e Peretz (1997), a memória interfere no processo de percepção. Assim sendo, é possível que a realização de atividades musicais antes da realização de um teste de percepção possa favorecer a memorização e, consequentemente, a identificação dos timbres ouvidos.

Outro dado que nos leva a defender uma possibilidade de comprovação da hipótese inicial é ainda o fato de que que a manipulação de instrumentos por meio de atividades como a composição, ou a execução musical, contribui para a formação de imagens auditivas (ou de representações mentais) que são acessadas durante a percepção de timbres, permitindo a identificação dos instrumentos ouvidos. De acordo com a teoria de Piaget (1990), as representações mentais são formadas por meio de ações realizadas sobre os objetos. No caso das representações sonoras, elas seriam formadas a partir da manipulação de instrumentos musicais. Especialmente no caso das crianças mais jovens, entre 7 e 10 anos de idade aproximadamente, é indispensável que ocorram experiências concretas sobre os objetos (DELVAL, 1998). No caso das crianças mais jovens, portanto, parece ser preciso que o indivíduo entre em contato direto com os instrumentos musicais para que forme representações apuradas desses objetos e, principalmente, do seu timbre. Por outro lado, é também possível que as representações mentais dos timbres instrumentais sejam formadas em função de experiências "abstratas”, ou ações mentais, como a audição.

Apesar de um bom número de fontes da literatura indicar uma possibilidade de comprovação da hipótese de que a aprendizagem de música por meio da realização de atividades de execução, composição e apreciação musical poderia favorecer o desenvolvimento da percepção de timbres, não devem ser ignoradas as pesquisas que apontam para uma negação dessa afirmativa. Como apontam os estudos de Háden, Stefanics, Vestergaard, Denham, Sziller e Winkler (2009) e Tsang e Trainor (2002), graças a possíveis experiências de aprendizagem não conduzida, até mesmo os bebês seriam sensíveis à percepção de timbres. Desse modo, é possível que a realização de aulas formais de execução, composição e apreciação musical tenha pouco ou nenhum efeito sobre a percepção de timbres, já que essa percepção vem se desenvolvendo desde o nascimento da criança graças a aprendizagens não conduzidas ou informais. 


\section{Metodologia}

\subsection{Participantes}

Este trabalho foi realizado com um grupo de 51 crianças com idades entre 6 e 9 anos. As crianças estudadas eram alunos de $1^{\mathrm{a}}$ e $2^{\mathrm{a}}$ série de uma escola pública do município de Campinas, no interior de São Paulo.

Os participantes foram randomicamente divididos em três grupos experimentais e em um grupo controle. Os grupos experimentais foram denominados grupo E, grupo C e grupo A, em função das atividades musicais de execução, composição e apreciação que foram realizadas com cada um deles. As crianças do grupo controle não realizaram atividades musicais durante a pesquisa.

Cada grupo foi composto por 13 crianças, com exceção do grupo experimental C, formado por 12 participantes. Cada grupo continha 5 alunos de $2^{\mathrm{a}}$ série e 8 alunos de $1^{\mathrm{a}}$ série, com exceção do grupo experimental C que contava com 7 alunos de $1^{\mathrm{a}}$ série. As médias de idade de cada um dos grupos estão apresentadas no quadro 1.

A distribuição de meninas e meninos entre os grupos também é apresentada no Quadro 1. O grupo controle e o grupo experimental A apresentam quase a mesma quantidade de participantes de cada um dos sexos. O grupo experimental $\mathrm{C}$ apresenta o dobro de meninas em relação ao número de meninos, e o grupo experimental E é formado por apenas dois meninos.

Quadro 1: médias de idade dos grupos estudados.

\begin{tabular}{|c|c|c|c|c|}
\hline & Controle & Grupo A & Grupo C & Grupo E \\
\hline Média de idade & 7,3333 & 7 & 7 & 7,0833 \\
\hline Sexo feminino & 6 & 6 & 8 & 11 \\
\hline Sexo masculino & 7 & 7 & 4 & 2 \\
\hline Total participantes & 13 & 13 & 12 & 13 \\
\hline
\end{tabular}

As crianças estudadas frequentavam aulas de Arte dentro da escola. Durante essas aulas eram trabalhadas as quatro linguagens artísticas - música, artes visuais, teatro e dança. Ao estudar conteúdos de música, os alunos usavam os seguintes instrumentos: voz, percussão corporal (palmas), clavas, latinhas, copos e forminhas improvisadas de metal. A professora tocava flauta doce e piano eletrônico durante as aulas. As atividades de música realizadas usualmente englobavam o canto, a prática de jogos rítmicos, a criação de ritmos ou de combinações rítmicas e a realização de apresentações dos trabalhos efetuados em sala.

Dentre as 51 crianças estudadas, apenas duas frequentavam aulas de música fora da escola regular. A família de uma das crianças não informou que tipo de aulas eram frequentadas, e a família do outro participante declarou que ele frequentou aulas de violão por 10 meses antes de participar do estudo. Esses dois participantes faziam parte do grupo experimental A.

De acordo com um questionário preenchido pelos pais das crianças, 57\% dos participantes ouvia música em casa diariamente, e $41 \%$ assistia a apresentações musicais gravadas em vídeo ou tocadas ao vivo com frequência de 1 a 3 dias por semana. Portanto, mais de metade dos participantes estava frequentemente exposta a música gravada e, com relativa frequência, boa parte das crianças estava exposta a gravações musicais em forma de vídeo ou a execuções ao vivo. 
Antes do início de todas as atividades, os participantes foram informados sobre a natureza do trabalho que seria realizado e foram questionados se gostariam ou não de participar dos procedimentos propostos. Os responsáveis pelas crianças também assinaram um termo de consentimento.

\subsection{Materiais}

Para este estudo foram utilizados os seguintes instrumentos musicais com os grupos experimentais $\mathrm{C}$ e E: um agogô, um par de crótalos, um par de pratos, um triângulo, um jogo de sinos (glockenspiel), uma pandeirola meia lua, um caxixi, um ovinho, um reco-reco, uma castanhola e a voz humana (voz dos participantes e do experimentador).

Para a gravação e exibição das faixas sonoras usadas no teste de percepção, e para a gravação e exibição da música usada durante a atividade de apreciação musical empreendida com o grupo experimental A, foi utilizado um computador Asus Eee equipado com microfone interno, o software de gravação Audacity e caixas de som de 2W usadas em potência máxima. As faixas apresentadas aos participantes foram gravadas com os mesmos instrumentos usados pelos grupos experimentais C e E.

Alguns dos instrumentos usados - como os pratos, o triângulo e a voz humana ${ }^{2}$ foram escolhidos em função de serem populares e poderem ser facilmente identificados pelos participantes do grupo controle. Outros, como os crótalos, o jogo de sinos e a castanhola, foram escolhidos por serem pouco comuns na música brasileira, e por serem instrumentos que possivelmente só viriam a ser conhecidos por meio das atividades musicais realizadas com os grupos experimentais. De modo geral, priorizou-se a utilização de instrumentos pequenos que pudessem ser facilmente manipulados pelas crianças.

Todos os participantes do estudo utilizaram um questionário de identificação de timbres composto por 10 questões e 1 questão de exemplificação. As alternativas de resposta foram dispostas em forma de figuras representando os instrumentos que deveriam ser identificados auditivamente ao longo do teste.

Os experimentos foram realizados na biblioteca da escola municipal que participou do estudo. Embora esse ambiente não fosse silencioso e sofresse interferência do som de atividades realizadas em sala próximas, ele era o local da escola com menor nível de ruído. A sala estava equipada com 5 mesas circulares e 11 cadeiras distribuídas entre as mesas, com uma mesa quadrada (mesa do professor) disposta de frente para o grupo de participantes. Nessa mesa foram dispostos o computador e as caixas de som usadas no teste de percepção.

\subsection{Procedimentos}

Este trabalho foi realizado por meio de um estudo experimental envolvendo um grupo controle e três grupos experimentais. Cada um dos grupos experimentais realizou uma atividade musical de aproximadamente 20 a 25 minutos antes da realização de um teste de percepção de timbres. Foram realizadas atividades de execução (grupo experimental E), de apreciação musical (grupo experimental A) e de composição (grupo experimental C) envolvendo os instrumentos musicais que deveriam ser percebidos no teste aplicado. $\mathrm{O}$ grupo controle não realizou nenhuma atividade musical. Todos os grupos foram submetidos a um teste de percepção de timbres. 
Antes da realização definitiva da coleta de dados, foi realizado um estudo piloto com 3 crianças em cada um dos grupos experimentais e com 2 crianças no grupo controle. Como não se optou por realizar transformações significativas nos procedimentos empregados, os dados colhidos durante o estudo piloto foram somados aos dados do estudo final e analisados em conjunto.

Durante a atividade de apreciação musical, realizada com o grupo experimental A, os participantes foram convidados a ouvir um arranjo do cânone "Doeba” de Rieks Veenker, elaborado para este estudo. O arranjo foi executado com vozes femininas e, durante a execução, foram adicionados solos instrumentais de castanhola, ovinho, caxixi, agogô, pandeirola, pratos, reco-reco, triângulo, jogo de sinos e crótalos (nesta ordem).

As crianças que receberam essa atividade ouviram o arranjo em sincronia com a observação de desenhos dos instrumentos executados. À medida que os instrumentos eram ouvidos, o experimentador apontava para o desenho correspondente. As crianças foram informadas como cada um dos instrumentos ouvidos é usualmente tocado, e em seguida foram convidadas a executar gestos imitando a execução de cada um dos instrumentos. Foi, então, proposto um jogo de execução de gestos em conjunto com os sons ouvidos, a semelhança de um jogo de "morto ou vivo". Os desenhos dos instrumentos ficaram disponíveis para visualização dos participantes durante toda a atividade. Os participantes não observaram nem tocaram os instrumentos reais.

Durante a atividade de execução musical os participantes do grupo experimental E foram convidados a executar os mesmo instrumentos abordados na atividade de apreciação sem que, contudo, pudessem manipular livremente cada um desses materiais.

As crianças foram inicialmente apresentadas aos instrumentos que seriam usados e receberam instruções sobre como cada um deles deveria ser tocado. Os participantes não puderam testar o som ou o modo de tocar os instrumentos antes do início da atividade. A todas as crianças foi proposto um jogo de execução musical. O experimentador apresentou a primeira parte da canção da Figura 1 (criada para o experimento) aos participantes, e demonstrou o ritmo em que os instrumentos deveriam ser tocados assim que seus nomes fossem mencionados. Após essas explicações, o jogo teve início com cada criança tocando um dos instrumentos musicais assim que o nome deste instrumento fosse ouvido. Após a execução de todos os instrumentos, a parte final da música era cantada. Esse jogo foi repetido até que todos os participantes pudessem tocar os 10 instrumentos usados na atividade.
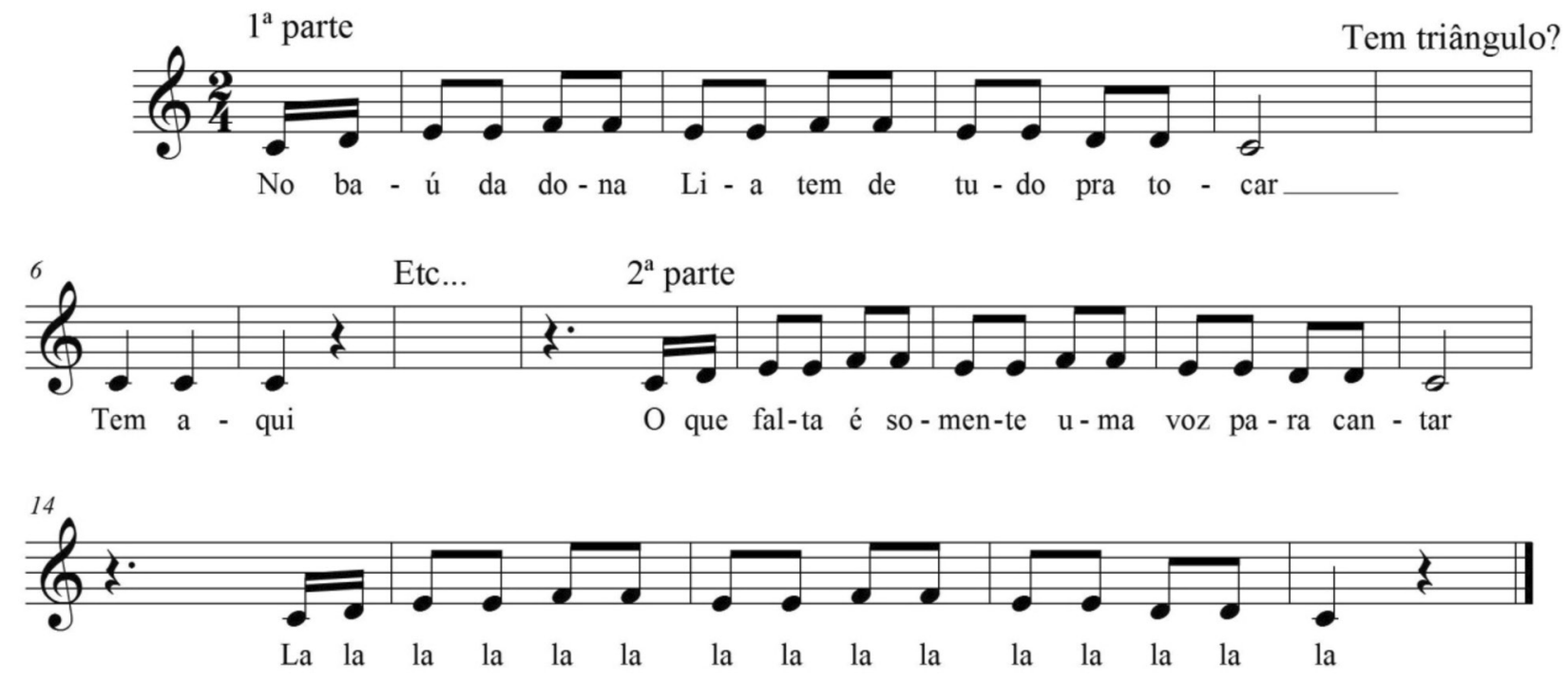

Figura 1: música usada na atividade de execução musical. 
Durante a atividade de composição, as crianças do grupo experimental C foram convidadas a explorar livremente cada um dos instrumentos disponíveis (os mesmo da atividade de execução). Cada criança teve o tempo de aproximadamente 30 segundos para produzir sons de forma livre com cada um dos instrumentos. Os materiais foram explorados em conjunto pelas crianças, portanto não era possível que cada participante ouvisse apenas o som do seu instrumento em ação. Todos os participantes exploraram todos os instrumentos usados nesta atividade.

Após essa exploração livre, as crianças foram convidadas a sonorizar a seguinte história, criada para esta pesquisa: era uma vez um gato que tinha medo de rato. Certa vez o gato subia a mesa à procura de leite quando viu um rato, sorrateiro, à procura de pão. Tamanho foi o susto e o pulo que o gato deu que, agarrando-se na toalha da mesa, ele fez com que todos os pratos viessem ao chão. Os participantes foram encorajados a buscar sons vocálicos ou sons produzidos com os instrumentos disponíveis que descrevessem os eventos narrados na história. Por fim, as crianças tocaram as sequências de sons escolhidos em conjunto com a narração da história, realizada pelo experimentador.

Logo após a realização das atividades musicais com os grupos experimentais, e no início dos trabalhos com o grupo controle, os participantes foram convidados a realizar um teste de percepção musical com duração total de 15 a 20 minutos. Neste teste as crianças foram convidadas a ouvir 11 trechos musicais de 15 segundos executados pela voz ou tocados em cada um dos instrumentos usados nas atividades musicais. Ao ouvirem cada um desses trechos os participantes foram convidados a preencher um questionário identificando o instrumento que foi ouvido. A primeira das faixas de áudio continha um exemplo musical gravado no ovinho. Esta faixa foi usada para exemplificar o modo como o questionário deveria ser preenchido. Os instrumentos das 10 faixas restantes foram identificados pelos participantes sem a ajuda do experimentador.

Como as crianças estavam dispostas em mesas circulares, e sentadas ao lado de 2 ou 3 colegas durante algumas situações do teste de percepção, elas foram instruídas a responder de forma independente, sem visualizar as respostas dos colegas. Embora a maioria das crianças tenha seguido as instruções, a ausência de mesas individuais de trabalho no ambiente utilizado pode ter interferido de forma não significativa ${ }^{3}$ na independência das respostas de alguns participantes.

\subsection{Análise de dados}

Os dados colhidos foram analisados de forma quantitativa e qualitativa. Foram empregadas análises de estatística descritiva para verificar a média de desempenho de cada um dos grupos no teste de percepção de timbres. Também foram traçadas as médias de desempenho dos participantes que manipularam instrumentos musicais (grupo E e grupo C) e dos participantes que não manipularam (grupo controle e grupo A).

Ainda foram empregadas análises estatísticas inferenciais ${ }^{4}$. Para verificar a existência de diferenças na percepção de timbres apresentada pelos grupos estudados, foram empregados os testes de análise de variância (ANOVA), teste t de Student e teste de Tukey. Ainda foi usado o teste de Mann-Whitney (teste U) para comparação da existência de semelhanças entre a população participante do grupo que manuseou (grupo C + grupo E) e do grupo que não manuseou (grupo $\mathrm{E}+$ grupo controle) os instrumentos musicais.

As análises qualitativas foram realizadas a partir da comparação das informações fornecidas pelos pais dos participantes e pela professora de Arte a respeito das vivências 
musicais das crianças, com as informações obtidas por meio da análise quantitativa dos resultados obtidos no teste de percepção.

\section{Resultados}

A média de desempenho dos participantes no teste de percepção de timbres é apresentada nos Gráficos 1 e 2. O primeiro gráfico apresenta os dados de cada um dos grupos em separado. De acordo com ele, os participantes do grupo E tiveram um desempenho ligeiramente melhor que o apresentado pelos participantes dos grupos $\mathrm{C}$ e A. O grupo controle apresentou a média de desempenho mais baixa.

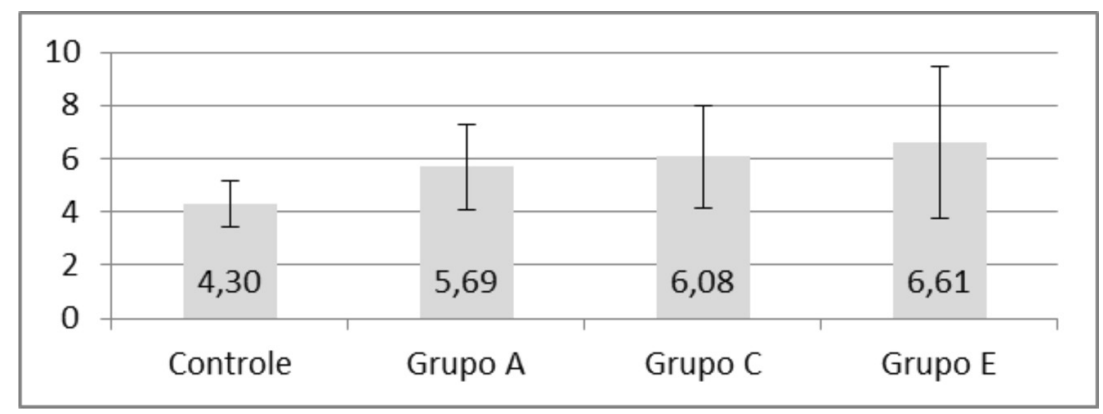

Gráfico 1: médias de desempenho de cada um dos grupos no teste de percepção de timbres, acompanhadas de erro padrão.

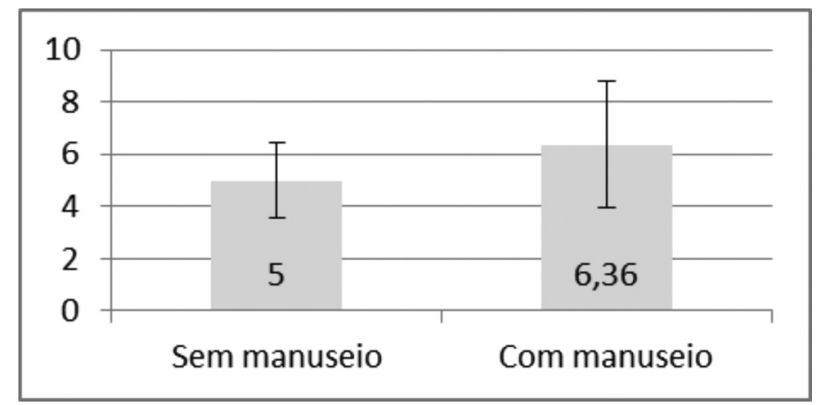

Gráfico 2: médias de desempenho dos grupos que manusearam os instrumentos usados no teste de percepção de timbres (grupos C e E) e dos grupos que não manusearam (grupo controle e grupo A), acompanhadas de erro padrão.

O segundo gráfico apresenta os dados dos grupos que manusearam os instrumentos musicais que foram usados no teste (grupo $\mathrm{C}+$ grupo E), comparados com os dados dos grupos que não manusearam esses instrumentos (grupo A + grupo controle). As crianças que tiveram contato direto com os instrumentos musicais ouvidos durante o teste de percepção tiveram melhor desempenho que as crianças que não manusearam esses materiais.

A realização de uma ANOVA sobre as médias do gráfico 1 demonstrou não existirem diferenças significativas entre o desempenho dos grupos no teste de percepção. $\mathrm{O}$ teste de Tukey realizado sobre esses mesmos dados também não apontou diferenças significativas entre as médias. A realização de uma série de testes t de Student apontou para a existência de diferenças significativas entre as médias do grupo controle e do grupo $\mathrm{E}(\mathrm{F}=8,2443$; $p=0,0140)$, entre as médias do grupo controle e do grupo $C(F=6,4940 ; p=0,0270)$, e entre as médias do grupo controle e do grupo A $(F=9,0419 ; p=0,0109)$.

A diferença entre as médias dos grupos que manusearam (grupo E e grupo C) e não manusearam (grupo controle e grupo A) os instrumentos, calculada por meio de uma ANOVA, se mostrou altamente significativa $(\mathrm{F}=12,5714 ; \mathrm{p}=0,0045)$. A realização de um teste $t$ de Student também apontou para a existência de uma diferença significativa entre o 
desempenho desses dois grupos $(\mathrm{F}=7,1367 ; \mathrm{p}=0,013350)$. A realização do teste de MannWhitney (teste U) apontou para a não existência de diferenças significativas entre a população do grupo dos participantes que manusearam os instrumentos e do grupo dos participantes que não manusearam.

\section{Discussão}

Este estudo procurou investigar o efeito da aprendizagem musical sobre a percepção de timbres. Mais especificamente, buscou investigar o efeito de atividades de execução, de apreciação e de composição musical sobre essa percepção.

Os resultados de uma ANOVA e de um teste de Tukey demonstraram não existirem diferenças significativas entre o desempenho dos grupos experimentais e do grupo controle no teste de percepção de timbres que foi realizado. Esse dado aponta para uma negação da hipótese inicialmente apresentada de que a aprendizagem musical favoreceria a percepção de timbres. Cada um dos grupos experimentais participou de uma espécie de aula de música antes da realização do teste de percepção. Essa aula parece não ter influído de forma significativa no desempenho das crianças dos grupos experimentais. Esse resultado é suportado pelas pesquisas de Bergan, Titze e Story (2004) e Lutfi, Oh, Storm e Alexander (2005).

Entretanto, esses resultados não são definitivos e não permitem a rejeição por completo da hipótese de que a educação musical teria efeitos sobre a percepção de timbres. As atividades musicais executadas com os participantes antes da realização dos testes foram bastante breves (com duração aproximada de 20 e 25 minutos). É possível que, durante esse reduzido período de tempo, não tenha ocorrido um processo de aprendizagem musical considerável. É possível também que, pelo fato de os participantes da pesquisa receberem aulas de música em sua escola regular, até mesmo as crianças do grupo controle tenham se beneficiado da educação musical para atingir os níveis que foram alcançados no teste de percepção de timbres. É possível ainda que esses mesmos participantes estejam sujeitos a aprendizagens musicais informais dentro de suas famílias. Segundo o questionário preenchido pelos pais das crianças envolvidas com a pesquisa, mais de metade delas ouvia música diariamente em casa. Portanto, boa parte dos participantes estava em contato constante com estímulos musicais ou com atividades de apreciação musical não conduzidas de modo formal.

Uma rejeição dos efeitos da educação musical também pode ser questionada porque uma análise mais detalhada, realizada por meio de uma série de testes t de Student, fornece resultados que comprovam a hipótese de que a aprendizagem musical favoreceria a percepção de timbres. Esses testes mostraram existirem diferenças significativas entre o desempenho dos três grupos experimentais e o desempenho do grupo controle. Eles comprovam, portanto, que a realização de atividades de execução, composição ou apreciação musical tem efeitos sobre a percepção de timbres em crianças de 6 a 9 anos de idade. Esses resultados estão em consonância com os estudos de Trainor, Wu e Tsang (2004), Shahin, Roberts, Chau, Trainor e Miller (2008) e Agus, Suied, Torpe e Pressnitzer (2012). Esses autores observaram que a aprendizagem musical favorecia a percepção de timbres.

O desempenho superior dos grupos experimentais também pode ser associado aos dados apontados por Paquette e Peretz (1997). Esses autores observaram que a memória tem influência sobre a percepção de timbres. É possível que as atividades de execução, composição e apreciação, realizadas imediatamente antes do teste de percepção, tenham levado à memorização dos timbres dos instrumentos manipulados ou ouvidos, e que essa memorização tenha favorecido o desempenho das crianças dos grupos experimentais no teste de percepção de timbres. 
Os resultados de uma ANOVA e de um teste t de Student, realizados sobre as médias de desempenho dos grupos que manipularam os instrumentos (grupos E e C) e que não manipularam (grupo controle e grupo A), apontou para a existência de uma diferença altamente significativa entre os resultados observados. As crianças que manipularam os instrumentos de forma livre, em uma atividade de composição, e as crianças que manipularam os instrumentos de forma direcionada, em uma atividade de execução musical, demonstraram melhor desempenho no teste de percepção que as crianças que apenas apreciaram uma música tocada com os mesmo instrumentos usados no teste ou que não realizaram nenhuma atividade musical. Esses dados são suportados pela teoria de Piaget (1990), que afirma que a manipulação de objetos concretos por crianças da faixa etária dos participantes deste estudo é a responsável pela formação de representações mentais - ou imagens auditivas. É possível que essas imagens tenham sido acessadas durante o teste de percepção de timbres e que elas tenham levado esses participantes a uma melhor identificação dos instrumentos tocados.

Estudos posteriores poderiam retomar essa comparação entre o desempenho de crianças que puderam ou não manipular os instrumentos musicais. Como esse não era o foco principal do presente trabalho, os grupos "com manipulação" e "sem manipulação" eram formados por participantes que realizaram atividades diferentes. Seria interessante a formação de grupos mais homogêneos em estudos futuros.

As discrepâncias entre os dados que negam e confirmam a hipótese de que a educação musical favorece a percepção de timbres, poderiam ser esclarecidas em futuros trabalhos. É possível que a realização de pesquisas com um número maior de participantes possa apontar para resultados mais conclusivos. A realização de estudos mais longos, durante os quais os participantes possam frequentar aulas maiores ou mesmo cursos de execução, apreciação ou composição musical, também poderia levar a dados mais consistentes a respeito do efeito da educação musical sobre a percepção de timbres.

Estudos desse gênero poderiam responder a questão que este trabalho deixa em aberto: qual das atividades musicais (apreciação, execução ou composição) leva a um melhor desenvolvimento da percepção de timbres? Essa questão não foi respondida porque o teste de Tukey - instrumento estatístico que poderia apontar uma resposta - mostrou a inexistência de diferenças significativas entre o desempenho dos grupos experimentais. De acordo com as médias de desempenho dos participantes, atividades de execução musical parecem favorecer a percepção de timbres. Estudos futuros poderiam abordar essa hipótese.

Através do presente estudo foi possível concluir que a realização de atividades de execução, composição e apreciação musical parece favorecer a percepção de timbres em maior medida que a não realização de atividades musicais por crianças com idades entre 6 e 9 anos. A aprendizagem musical parece interferir, portanto, na percepção de timbres.

\section{Notas}

1 Optamos por adotar o termo "execução" em lugar de "performance” porque o primeiro é mais comumente utilizado pelos tradutores de Swanwick e de seu modelo (T)EC(L)A, usados como referencial ao longo deste artigo. O modelo (T)EC(L)A propõe que a educação musical ocorra por meio de atividades relacionadas à técnica, execução, composição, literatura e apreciação - cada uma das letras da palavra "(T)EC(L)A" corresponde a um dos tipos de envolvimento com a música mencionados. Também utilizaremos o verbo "executar" como sinônimo para a ação de tocar um instrumento/cantar a fim de manter a relação com o referencial teórico adotado.

2 Como aponta o estudo de Agus, Suied, Torpe e Pressnitzer (2012), a voz humana é o timbre mais facilmente percebido.

3 Essa interferência foi julgada como não significativa porque nenhum dos participantes que copiou respostas conseguiu copiar uma resposta correta. Ou seja, se essa criança houvesse deixado sua resposta em branco, ela teria o mesmo desempenho que obteve ao copiar uma resposta incorreta. 
4 As análises de estatística inferencial foram realizadas sob a orientação do professor Danilo Ramos dentro do contexto da disciplina de Pós-Graduação de Seminários Avançados, na Universidade Estadual de Campinas.

\section{Referências}

AGUS, T. R.; SUIED, C.; TORPE, S. J.; PRESSNITZER, D. Fast recognition of musical sounds based on timbre. Journal of the Acoustic Society of America, v.131, n.5, p. 4124-4133, 2012.

AUCOUTURIER, J. J.; PACHET, F.. The influence of polyphony on the dynamical modeling of musical timbre. Pattern Recognition Letters, v.28, p. 654-661, 2006.

BERGAN, C. C.; TITZE, I. R.; STORY, B. The perception of two vocal qualities in a synthesized vocal utterance: ring and pressed voice. Journal of Voice, v.18, n.3, p. 305-317, 2004.

BRANCUCCI, A.; MARTINI, P. S. Laterality in the perception of temporal cues of musical timbre. Neuropsychologia, v.37, p. 1445-1451, 1999.

DELVAL, J. Crescer e pensar: a construção do conhecimento na escola. Porto Alegre: Artes Médicas, 1998.

HÁDEN, G. P.; STEFANICS, G.; VESTERGAARD, M. D.; DENHAM, S. L.; SZILLER, I.; WINKLER, I. Timbre-independent extraction of pitch in newborn infants. Psychophysiology, v.46, p. 69-74, 2009.

IVERSON, P.; KRUMHANSI, C. L. Isolating the dynamic attributes of musical timbre. Journal of the Acoustic Society of America, v.94, n.5, p. 2595-2603, 1993.

LUTFI, R. A.; OH, E.; STORM, E.; ALEXANDER, J. M. Classification and identification of recorded and synthesized impact sounds by practiced listeners, musicians, and nonmusicians. Journal of the Acoustic Society of America, v.118, n.1, p. 393-404, 2005.

PAQUETE, C.; PERETZ, I. Role of familiarity in auditory discrimination of musical instrument: a laterality study. Cortex, v.33, p. 689-696, 1997.

PIAGET, J. A formação do símbolo na criança: imitação, jogo e sonho, imagem e representação. 3. ed. Rio de Janeiro: LTC, 1990.

SAMSOM, S.; ZATORRE, R. J. Contribution of the right temporal lobe to musical timbre discrimination. Neuropsychologia, v.32, n.2, p. 231-240, 1994.

SHAHIN, A. J.; ROBERTS, L. E.; CHAU, W.; TRAINOR, L. J.; MILLER, L. M. Music training leads to the development of timbre-specific gamma band activity. Neuroimage, v.41, p. 103-122, 2008.

SWANWICK, K. A basis for music education. London: Routledge, 1979.

TRAINOR, L. J.; WU, L.; TSANG, C. D. Long-term memory for music: infants remember tempo and timbre. Developmental Science, v., n.3, p. 289-296, 2004.

TSANG, C. D.; TRAINOR, L. J. Spectral slope discrimination in infancy: sensitivity to socially important timbres. Infant Behavior and Development, v.25, p. 183-194, 2002.

Caroline Caregnato - Formada em Educação Artística - Artes Plásticas pela Universidade Federal do Paraná, e em Licenciatura em Música pela Escola de Música e Belas Artes do Paraná. É mestre em Música pela Universidade Federal do Paraná e aluna do doutorado em Música da Universidade Estadual de Campinas. É professora assistente da Universidade do Estado do Amazonas e realiza pesquisas na área de Cognição e Educação Musical. 